\title{
从绿色施工管理理念分析建筑施工管理的创新
}

\author{
郭峰
}

克拉玛依通运实业有限责任公司

DOI:10.32629/btr.v1i4.1608

[摘 要] 最近几年, 我国建筑工程施工行业发展速度在不断加快, 这与我国社会的整体经济增长有直接关系, 人们的环保理念 也在不断的提升,对于建筑工程施工行业的期望值也变得越来越高了,保护生态环境就是在保护人们自己。现阶段,世界各国在 现代化建设的过程中,环境污染以及生态污染变得越来越严重,这些现象的出现在很大程度上唤醒了人们保护自然的意识,使 人们心中的绿色观念开始不断生长。通常情况下, 施工企业在展开建筑工程施工的时候, 往往会对周围环境造成较为严重的污 染,很难在短时间复原, 面对现阶段行业发展的形式,相关工作人员应该对施工管理的理念进行积极转变,从而更加促进企业的 发展。

[关键词] 绿色施工; 管理理念; 创新探索

随着时代的进步, 绿色施工的管理理念开始不断迈进人 们的视野, 并且给整个行业的发展注入了新鲜的血液, 在进 行建筑施工的过程中, 绿色施工管理理念已经成为了建筑行 业发展的新趋势。目前, 我国很多建筑工程施工企业在实际 工作展开的时候面临着一些问题, 主要是由于企业的管理制 度并不完善、相关管理人员的环保意识相对较差等等, 由于 这样的一系列问题导致了施工监管质量不高。所以, 在展开 建筑工程施工管理工作的时候, 应该注意对现阶段的实际情 况进行精准的把握, 要坚持树立绿色施工的理念。绿色施工 理念体现在多个方面, 主要包括对建筑工程材料的选择、施 工设备的选择以及施工技术的选择等等, 只有以上几个方面 都达到标准要求之后, 才能够保证建筑工程施工的绿色管理 能够发挥出应有的作用 ${ }^{[1]}$ 。

\section{1 绿色施工的管理理念}

近几年, 随着我国社会经济的不断增长, 建筑工程施工 行业的发展也在不断加快, 人们对于建筑行业的期望值也在 不断提升。建筑工程施工行业在接下来的发展过程中, 要明 确发展理念, 施工过程中尽量减小对自然环境以及生态环境 的污染, 从而实现对资源循环利用 ${ }^{[2]}$ 。绿色施工理念对于建 筑工程施工管理有重要的意义, 现今社会, 我们生活的环境 屡遭破坏, 绿色施工已经成为了时代发展的主题, 绿色施工 是社会的集体共识, 建筑工程施工行业的发展已经进入到了 一个全新的时期, 许多行业在运转的过程中都会对环境造成 一定的污染, 尤其是对于建筑工程施工行业来说, 对环境的 污染越来越严重, 企业相关技术人员应该不断加强的施工工 艺以及管理模式的研究, 从而减小施工过程中对于环境的污 染。除此之外, 很多企业还存在着材料浪费严重以及环保意 识薄弱的问题, 在今后工作展开的过程中, 人们应该注意对 施工绿色管理的理念进行积极的创新。

\section{2 现阶段我国建筑工程施工管理过程中存在的问题}

2.1 绿色观念较为薄弱

现阶段, 对于我国很多的建筑工程企业来说, 绿色施工
的理念还相对薄弱, 无论是施工理念还是施工管理理念都有 所欠缺, 现今社会, 环保意识是非常重要的, 绿色理念已经越 来越引起人民群众的重视以及响应了, 从我国现阶段施工管 理的整体上看, 绿色观念还只是停留在一个较低的层面上, 大多数的建筑施工人员以及管理人员脑海中并没有较为具 体的绿色施工理念, 这也就直接导致了建筑工程施工工作在 展开的过程中经常会对生态环境造成一定的破坏, 并且这种 破坏往往是长期性的、反复性的。在实际施工展开的过程中, 很多施工企业对于经济利益的追求远远高于一切, 这也就导 致了人们往往忽略了环保的重要性, 从而在很大程度上加大 了绿色施工项目建设的难度 ${ }^{[3]}$ 。

\section{2 技术水平有限}

我国也有很大一部分建筑工程施工企业开始展开了绿 色施工以及管理工作, 并且制定了较为完善的施工管理体系, 但是实际施工的过程中往往没有取得理想的效果, 这主要与 现阶段我国绿色施工的技术水平还较为有限, 不能够很好的 满足行业整体发展的需求, 这样的现象也在很大程度上影响 了我国绿色施工管理人员的技术提升, 由于硬件支持没有达 到标准, 人员自身的专业素质也自然会长时间的停滞不前, 这无论是对员工来说, 还是对企业来说, 都是非常不利的。同 时, 也会严重的影响到最终的施工效果。

\section{3 监管力度相对较差}

对于一般的建筑工程施工企业来说, 监管力度会直接关 系到最终的施工质量。通常情况下, 很多建筑企业在进行施 工管理的时候往往只是看中工程的质量以及安全, 将工程质 量当做唯一重点检查目标, 一旦工程的整体质量达到标准, 就认定为建筑工程施工合格, 这就会在很大程度上导致建筑 工程行业在施工的时候对环境保护越来越不重视, 往往会忽 略监管人员的重要性, 长期以往, 绿色施工的理念很难真正 落实到工作当中 ${ }^{[4]}$ 。

\section{3 绿色施工的管理理念创新措施}

3.1 节约施工材料的应用, 加大施工管理力度 
对于绿色施工的管理理念进行创新是非常有必要的, 并 且创新意识不能是短时间的, 应该长期坚持下去, 很多施工 队伍在施工的过程中没有对材料进行精准的预支, 这就导致 材料浪费的情况很容易出现。在施工的过程中, 相关施工工 作人员应该注意对设备进行爱惜使用, 要定期对设备进行维 修以及养护工作, 并且要时时刻刻保证其处于最佳工作状态, 当设备在应用过程中很少出现意外情况的时候, 也就会在一 定程度上降低了设备运行的成本。

\section{2 做好对施工废物的处理工作}

对于建筑工程施工工作来说, 一定会产生很多的废物垃 圾, 如果没有对其进行及时的处理, 很容易对环境造成污染, 同时也会对周围居民的正常生活以及工作造成一定的影响。 传统的施工废物处理方法较为单一, 并且整体效果也很不理 想, 大多是将废物放置于某一个指定的地方, 然后便不了了 之, 这样虽然对环境的污染有所减小, 但还是很容易造成污 染, 这会给绿色施工以及管理造成一定的麻烦。在进行绿色 施工管理的时候, 应该特备注意对于废弃物的处理 ${ }^{[5]}$ 。首先, 对于那些可以进行二次利用的废弃物来说, 应该将其收拾起 来, 然后进行统一的处理, 通常是留作二次利用, 这样可以一 定程度上节省施工材料, 同时也节省了施工的成本。其次, 在对不可回收的垃圾或者是废物进行处理的时候, 应该对其 进行分类, 按照类别的不同来进行不同的处理。

\section{3 大力宣传绿色施工方案}

在进行建筑工程绿色施工的时候, 除了要保证施工的质 量之外, 还要尽量避免施工过程对环境造成危害, 施工管理 工作对于建筑施工来说是非常重要的, 在进行绿色环保施工 的过程中, 应该注意对施工中的各个环节进行精准的掌控, 从而保证整体的施工质量。在施工管理过程中, 要将绿色管 理的理念融入到整个施工方案当中, 并且要对绿色施工理念 进行不断的完善, 通常情况下, 在对建筑施工管理方案进行 制定的时候, 要根据项目的实际情况来进行, 这是非常关键 的, 无论是在施工理念上, 还是在施工的行动上都应该将绿 色施工的理念放在第一位 ${ }^{[6]}$ 。在进行建筑工程现场施工的时 候, 相关施工管理人员要对现场的实际情况有较为清晰的掌 握, 并且对施工过程中是否存在污染以及浪费的情况进行核
查,一旦发现这种情况, 要对管理人员以及涉事部门进行严 肃处理。

3.4 加大对于绿色施工材料的使用力度

现阶段, 我国很大一部分施工企业在展开施工工作的时 候, 往往重视对绿色施工材料的应用, 这也就导致工程的整 体环保效果并不明显。建筑工程施工材料的选择会在很大程 度上影响到整体建筑施工的效率, 想要做到绿色施工, 就应 该按照建筑企业的要求来对施工材料进行准确的选择, 通常 会选择对环境污染小并且造价相对较低的材料, 这就要求施 工方对施工材料施工有较为全面透彻的了解, 应该成立针对 本次项目的调研小组, 对市面上与此次项目施工相关的材料 性价比进行调研, 从而确定最终的材料选用方案 ${ }^{[7]}$ 。

\section{4 结束语}

建筑工程绿色施工管理工作的发展理念与现阶段时代 大环境是相符合的, 综上所述, 建筑工程施工企业应该始终 坚定绿色发展的理念, 这样不仅仅对我国环境保护工作的展 开起到重要帮助, 同时, 也会使企业得到长远稳定的发展。对 于建筑工程企业来说, 还需要积极的引进先进的机械设备以 及管理理念, 并且要始终保持着谦卑的学习态度, 才能够保 证企业整体素质得到长久的提升。

[参考文献]

[1]廖飞.从绿色施工管理理念分析建筑施工管理的创 新[J].建筑与装饰,2018,17(11):47+51.

[2]刘耀军.从绿色施工管理理念分析建筑施工管理的创 新[J].建筑工程技术与设计,2018,29(13):2059。

[3]徐世姣,郑楠,张娓.从绿色施工管理理念分析建筑施 工管理的创新[J].中国房地产业,2018,33(4):107.

[4]姜宇鹏,徐鸿君.从绿色施工管理理念分析建筑施工 管理的创新[J].中国房地产业,2017,9(26):135。

[5]王晶晶. 从绿色施工管理理念分析建筑施工管理的创 新[J].魅力中国,2016,2(46):37.

[6]罗志辉. 基于绿色施工管理理念下如何创新建筑施工 管理[J].装饰装修天地,2018,14(14):71.

[7]胡德华.基于绿色施工管理理念下如何创新建筑施工 管理[J].建筑工程技术与设计,2018,13(14):3982. 